DOI: $10.17805 /$ zpu.2016.4.9

\title{
Оценки молодежи неперспективных трансгуманистических технологий изменений человека*
}

\author{
В. А. ЛУКОВ \\ (МОСКОВСКИЙ ГУМАНИТАРНЫЙ УНИВЕРСИТЕТ)
}

Статья посвящена изучению взглядов российской молодежи на неперспективные трансгуманистические технологии изменений человека. За основу взяты данные исследования, проведенного в Анадыре, Белгороде, Братске, Екатеринбурге, Иркутске, Кызыле, Москве, Новосибирске, Орле, Якутске и других городах России, осуществленного Московским гуманитарным университетом. В исследовании выделялись две группы респондентов: одна представляла те категории молодежи, которые так или иначе связаны с реализацией планов по улучшению человеческой жизни (медики, биологи, биотехнологи и др.); другая группа включала молодежь, профессиональная идентичность которой не связана с улучшением жизни человека (историки, социологи, экономисты, менеджеры и др.). Исследование показало, что неперспективными трансгуманистическими технологиями изменений человека и та и другая группы считают примерно одни и те же позиции. И эти позиции в той или иной мере являются ныне осуществляемыми в рамках биотехнологических решений применительно к отдельным человеческим особям.

Качественные исследования, проведенные среди молодых медиков, практически реализующих меры в области восстановления человека, показали автору, что анкетные ответы не содержат точные представления этой группы о неперспективных трансгуманистических технологиях. Это во многом связано с тем, что в своих ответах молодые медики ориентируются не на личный опыт, а на принятые в обществе представления об эффективности изменений человека.

Ключевые слова: биосоциология; трансгуманизм; российская молодежь; общественное мнение; идентичность с профессией

\section{ВВЕАЕНИЕ}

Иосоциология молодежи дает новый взгляд на проблему улучшения человека. D Важная задача биосоциологии - выявить возможные трансформации общества через накопление в новых поколениях критической массы биологических и интеллектуальных (под воздействием факторов внешней среды обитания и вызванных искусственными средствами), а также социокультурных изменений (Иуков, 2011, 2015).

* Выполнено при поддержке Российского научного фонда (грант № 15-18-30057/16).

The article was written within the framework of a project supported by the Russian Science Foundation (Grant No. 15-18-30057/16). 
Многие вопросы концепции улучшения человека определены в статьях Б. Г. Юдина и П.А. Тищенко (Тищенко, 2014; Тищенко, Юдин, 2015) и др. Ими, в частности, даны основные характеристики биоэтического понимания природы человека и возможные границы его (человека) улучшения с опорой на современные трактовки западных мыслителей. Е. Г. Гребенщикова отмечает сложность этической проблематики, связанной с развитием технологий «исчисления себя» (Гребенщикова, 2015). Б. Г. Юдин специально останавливается на вопросах трансдисциплинарности гуманитарной экспертизы, что для нас очень важно при изучении молодежного общественного мнения (Юдин, 2015). В ином аспекте, но крайне полезном для нашего исследования, трактует вопросы гуманитарной экспертизы В. А. Аапшин, проводя исследование среди молодых инвалидов, но пользуясь нашей системой вопросов (Аапшин, 2016). Б. Г. Юдиным и другими дается также критика трансгуманистического взгляда на перспективу человека (Юдин, 2014).

В настоящей статье ставится целью изучение взглядов российской молодежи на неперспективные трансгуманистические технологии изменений человека.

\section{МЕТОАИЧЕСКИЕ ВОПРОСЫ ПРОВЕАЕНИЯ ИССАЕАОВАНИЯ РОССИЙСКОЙ МОАОАЕКИ}

Исследования российской молодежи в контексте проблемы возможного «улучшения» человека были проведены по нашему инструментарию Московским гуманитарным университетом, группой социологов под руководством профессора А. И. Ковалевой. Была использована квотная выборка. Всего было опрошено 733 молодых человека, часть из которых получают образование или работают в сфере медицины и биологии, а часть - по специальностям, непосредственно не предполагающим проблематику изменения человеческой природы. Квоты были выбраны в следующих научно-исследовательских и образовательных учреждениях: ФГБОУ ВО «Российский экономический университет им. Г. В. Плеханова» (г. Москва); Сибирский институт управления Российской академии народного хозяйства и государственной службы при Президенте Российской Федерации (г. Новосибирск); ФГАОУ ВО «Белгородский государственный национальный исследовательский университет» (г. Белгород); ФГБОУ ВО «Иркутский государственный университет» в городе Братске (г. Братск); ФГБОУ ВО «Иркутский государственный медицинский университет» (г. Иркутск); ФГБОУ ВО «Иркутский государственный университет» (г. Иркутск); ФГБОУ ВО «Калмыцкий государственный университет имени Б. Б. Городовикова» (г. Элиста); ФГОУ «Московский государственный гуманитарно-экономический университет» (г. Москва); ФГБОУ ВО «Первый Московский государственный медицинский университет им. И. М. Сеченова» (г. Москва); АНО ВО «Московский гуманитарный университет» (г. Москва); ФГБОУ ВО «Новосибирский государственный медицинский университет» (г. Новосибирск); ФГБОУ ВО «Новосибирский государственный педагогический университет» (г. Новосибирск); ННОУ ВПО «Национальный институт бизнеса» (г. Москва); научно-исследовательские и опытно-конструкторские работы; Орловский филиал Российской академии народного хозяйства и государственной службы при Президенте Российской Федерации (г. Орел); Северо-Восточный федеральный университет им. М. К. Аммосова (г. Якутск); ФГБОУ ВО «Тувинский государственный университет» (г. Кызыл); ФГБОУ ВО «Уральский государственный лесотехнический университет» (г. Екатеринбург); ГБУЗ СО Центр специализированных видов медицинской помощи «Уральский институт травматологии и ортопедии имени В. А. Чаклина» (г. Екатеринбург); 
ФГБОУ ВО «Уральский государственный юридический университет» (г. Екатеринбург); Чукотский филиал Северо-Восточного университета им. М. К. Аммосова (г. Анадырь). Использованы также материалы Школы молодых ученых (г. Белгород), где собрались молодые специалисты по биотехнологиям (Концепции ..., 2016).

Научно-исследовательские учреждения и вузы были выбраны с таким расчетом, чтобы европейская традиция трансгуманизма не слишком сильно давала о себе знать. Между тем и позитивные представления об изменениях человека, и опасения таких изменений, которые покушаются на природу человека, были нами взяты из документов и меморандумов трансгуманистического движения (FM-2030, 1970, 1973, 1977).

Большинство респондентов ничего не знают о трансгуманистическом движении и его лидерах. Тем не менее они с интересом и охотно отвечают на вопросы о перспективах человека.

\section{НЕПЕРСПЕКТИВНЫЕ ТЕХНОАОГИИ \\ В ОБЩЕСТВЕННОМ МНЕНИИ МОАОАЕЖИ}

Мы уже показали, что принципиальной разницы нет между ответами тех, кто пришел обучаться на гуманитарные специальности, и тех, кто работает или планирует работу в сфере медицины и биологии, в вопросах, касающихся перспектив «улучшения» человека. Что же касается опасений об изменении природы человека, то картина такова (см. табл. 1, с. 118).

С учетом этого небезынтересно, что значительная часть участвовавших в исследовании молодых людей вполне определенно признают перспективными для «улучшения человека» трансгуманистический набор основных путей воздействия на его природу. Относительно киборгизации число положительных выборов вместе с «сомневающимися» (не определившимися с ответом или не давшими его) составляет около половины всех респондентов.

Здесь имеет значение стремление трансгуманистов к созданию форсайтов будущего, которые на практике нередко оказываются псевдофорсайтами, воспринимаемыми молодежью без разделения на подлинные и надуманные.

Распространение практики проведения псевдофорсайтов может оказывать негативное влияние на общество в целом и молодежь в частности. Популярность форсайта в научном сообществе растет, а число таких исследований увеличивается, у исследователей появляется стремление выдавать за форсайт проекты, которые по сути таковыми не являются (например, российский форсайт-проект «Аетство 2030» (2008-2011 гг.), см.: Малахова, 2014: Электронный ресурс).

Что же касается неперспективных технологий, то на первое место и среди первой, и среди второй групп выходит управление полом неродившегося ребенка. В первой группе (биологи, медики) эта позиция характерна для 49,7\%, во второй - для 47\%. Как видим, профессиональная ориентированность не имеет значения для этого выбора. А что же имеет значение? Исследование показало, что существенно больше выборов принадлежит девушкам, нежели юношам всего обследуемого контингента. Иными словами, на выбор этой позиции в минимальной степени влияет ориентация на действительные изменения в медицинском аспекте этой биотехнологии. Гораздо большее значение в российской культуре имеет традиционное разделение по полам. Эта дистанция видна как на Аальнем Востоке (Чукотка), так и в среднеевропейской России (Белгород, Орел и др.) и имеет культурологическое, а не биотехнологическое основание. 
Таблича 1

РАСПРЕАЕАЕНИЕ ОТВЕТОВ ПО ВОПРОСУ «КАКИЕ ТЕХНО ОГИЧЕСКИЕ РЕШЕНИЯ ВЫ СЧИТАЕТЕ ОПАСНЫМИ ААЯ ЗАОРОВЬЯ ЧЕ ОВЕКА И ЕГО БУАУЩЕГО СУЩЕСТВОВАНИЯ?»

Table 1

FREQUENCY DISTRIBUTION OF RESPONSES TO THE QUESTION “WHICH TECHNOLOGIES DO YOU CONSIDER DANGEROUS FOR THE HEALTH AND FUTURE OF MANKIND?

\begin{tabular}{|c|c|c|c|c|}
\hline \multirow{2}{*}{$\begin{array}{c}\text { Какие технологические решения } \\
\text { Выс считаете опасньми } \\
\text { для здоровья человека } \\
\text { и его будущего существования? }\end{array}$} & \multicolumn{2}{|c|}{ Биолог, медик } & \multicolumn{2}{|c|}{ Аругие спечиальности } \\
\hline & aбc & $\%$ & aбc & $\%$ \\
\hline $\begin{array}{l}\text { генномодифицированные продукты } \\
\text { питания }\end{array}$ & 69 & 46,3 & 276 & 48,4 \\
\hline $\begin{array}{l}\text { управление полом неродившегося } \\
\text { ребенка }\end{array}$ & 74 & 49,7 & 268 & 47,0 \\
\hline $\begin{array}{l}\text { изменение пола при помощи } \\
\text { хирургического вмешательства }\end{array}$ & 66 & 44,3 & 247 & 43,3 \\
\hline $\begin{array}{l}\text { нейролингвистическое } \\
\text { программирование }\end{array}$ & 26 & 17,4 & 98 & 17,2 \\
\hline клонирование человека & 67 & 45,0 & 222 & 38.9 \\
\hline $\begin{array}{r}\text { ксенотрансплантация (пересадка } \\
\text { органов от животных человеку) }\end{array}$ & 50 & 33,6 & 276 & 48.4 \\
\hline использование органов умерших людей & 25 & 16,8 & 123 & 21,6 \\
\hline Аругое & 3 & 2,0 & 4 & 0,7 \\
\hline $\begin{array}{l}\text { указанные технологии не настолько } \\
\text { опасны для человека, как об этом } \\
\text { говорят некоторые ученые }\end{array}$ & & & & \\
\hline и журналисты & 14 & 9,4 & 42 & 7,4 \\
\hline пальмовое масло & - & - & 1 & 0,2 \\
\hline ядерное оружие & - & - & 1 & 0,2 \\
\hline полная киборгизация человека & - & - & 1 & 0,2 \\
\hline все опасны & - & - & 1 & 0,2 \\
\hline вживление чипов в тело человека & 1 & 0,7 & - & - \\
\hline $\begin{array}{l}\text { создание генномодифицированных } \\
\text { лекарств }\end{array}$ & 1 & 0,7 & - & - \\
\hline
\end{tabular}

\section{КАЧЕСТВЕННАЯ СТРАТЕГИЯ В ИССАЕАОВАНИИ МОАОАЕЖНЫХ ОЦЕНОК}

Молодежные оценки нередко несут в себе принятые в обществе приоритеты, взятые из СМИ, разговоров в семье и т. А. Качественные исследования молодежной среды, таким образом, становятся важным источником представлений исследователей о действительных намерениях молодежи при ответе на трудные для молодого возраста вопросы. В нашем случае мы сталкиваемся именно с такой ситуацией. С одной стороны, медики и биологи лишь в будущем будут таковыми, в момент опроса они лишь планируют свое профессиональное будущее. С другой стороны, они уже сейчас поль- 
зуются иными источниками, чем лица, намеревающиеся получить специальность в области гуманитарных наук.

В литературе уже высказывались гипотезы о том, что молодые люди знают преимущественно литературные произведения своего времени, не догадываясь, что тема «улучшения человека» присутствует в них уже много веков (Ауков, Павлов, 2015: Электронный ресурс). Исследование показало обоснованность такого гипотетического представления (см. табл. 2).

Таблича 2

РАСПРЕАЕ АЕНИЕ ОТВЕТОВ НА ЗНАНИЕ СВЕРСТНИКАМИ САЕАУЮЩИХ АИТЕРАТУРНЫХ ГЕРОЕВ И КИНОПЕРСОНАЖЕЙ (В \%) Table 2

FREQUENCY DISTRIBUTION OF RESPONSES TO QUESTIONS ON BEING FAMILIAR WITH CERTAIN CHARACTERS IN LITERATURE AND CINEMA (\%)

\begin{tabular}{|c|c|c|c|}
\hline $\begin{array}{c}\text { По какой спечиальности (направлению } \\
\text { подготовки) Вы получили ( получаете } \\
\text { в настоящее время) высшее образование? }\end{array}$ & $\begin{array}{c}\text { Он хорошо } \\
\text { известен }\end{array}$ & $\begin{array}{c}\text { Он никому } \\
\text { не известен }\end{array}$ & $\begin{array}{l}\text { Трудно } \\
\text { сказать }\end{array}$ \\
\hline $\begin{array}{c}\text { Голем } \\
\text { биолог, медик } \\
\text { другие специальности }\end{array}$ & $\begin{array}{l}30,8 \\
30,7\end{array}$ & $\begin{array}{l}23,1 \\
17,9\end{array}$ & $\begin{array}{l}44,9 \\
50,5\end{array}$ \\
\hline $\begin{array}{l}\text { Профессор Аоуэль } \\
\text { биолог, медик } \\
\text { Аругие специальности }\end{array}$ & $\begin{array}{l}25,6 \\
24,3\end{array}$ & $\begin{array}{l}21,8 \\
25,7\end{array}$ & $\begin{array}{l}51,3 \\
49,3\end{array}$ \\
\hline $\begin{array}{c}\text { Франкенштейн } \\
\text { биолог, медик } \\
\text { Аругие специальности }\end{array}$ & $\begin{array}{l}84,0 \\
90,8\end{array}$ & $\begin{array}{l}0,6 \\
0,9\end{array}$ & $\begin{array}{c}15,4 \\
7,8\end{array}$ \\
\hline $\begin{array}{c}\text { Робокоп } \\
\text { биолог, медик } \\
\text { другие специальности }\end{array}$ & $\begin{array}{l}71,8 \\
86,3\end{array}$ & $\begin{array}{l}2,6 \\
2,3\end{array}$ & $\begin{array}{l}25,6 \\
10,8\end{array}$ \\
\hline $\begin{array}{c}\text { Терминатор } \\
\text { биолог, медик } \\
\text { другие специальности }\end{array}$ & $\begin{array}{l}84,0 \\
93,8\end{array}$ & $\begin{array}{l}0,6 \\
0,7\end{array}$ & $\begin{array}{c}15,4 \\
5,0\end{array}$ \\
\hline
\end{tabular}

Качественный анализ показывает, что здесь нет ошибки.

Мы имели возможность наблюдать группу молодых медиков (средний медицинский персонал), непосредственно занимающихся реанимацией больных, имеющих сердечно-сосудистые заболевания. Аевушки не планируют, как правило, свое дальнейшее обучение в медицинском вузе, хотя работы по реабилитации больных ведут профессионально. Они в основном рассчитывают успешно выйти замуж, понимая, что их навыки медицинских работников могут им пригодиться в семейной жизни. Юноши, напротив, продолжают повышать свой профессиональный уровень, рассматривая для 
себя обучение в вузе как обязательный элемент жизненного продвижения. И те, и другие подобно их сверстникам не обладают элементарными знаниями, например, они одинаково не знают столиц Болгарии, Венгрии и ряда других европейских стран. Но в то же время их жизненный опыт уже достаточен, чтобы решать для себя проблемы «улучшения человека». Они в одинаковой степени уверены, что для большинства их больных такое «улучшение» не только не необходимо, но и ничего не позитивного в себе не несет. Большинство больных для них представляют собой людей, «отживших свой век», и нет никакой необходимости продлевать их жизнь. Именно в таком духе эти молодые медики высказывают свое мнение о перспективах человека, а в анкетах на такие вопросы отвечают так, как это принято в обществе.

\section{МОАОАЕЖЬ: НАДЕЖАЫ НА МОАОАЕЖЬ}

При том, что взгляды на «улучшение» человека в молодежной среде не определяются профессиональными позициями, значительная часть ответивших на вопросы исходит из того, что именно молодежь определит границы этого «улучшения» в ближайшие годы.

В анкете содержался вопрос о согласии респондентов с тем, что молодежь выражает передовые идеи нашего времени, в том числе и в отношении к «улучшению человека». Были получены следующие данные (см. табл. 3).

\section{РАСПРЕАЕАЕНИЯ СОЦИААЬНЫХ ОЖИААНИЙ И ОПАСЕНИЙ (В \%)}

Таблица 3

FREQUENCY DISTRIBUTION OF SOCIAL HOPES AND FEARS (\%)

Table 3

\begin{tabular}{|c|c|c|c|c|c|}
\hline \multirow{2}{*}{$\begin{array}{c}\text { По какой спечиальности } \\
\text { (направлению подготовки) } \\
\text { Вы получили (получаете } \\
\text { в настолщее время) } \\
\text { высшее образование? }\end{array}$} & \multicolumn{5}{|c|}{$\begin{array}{c}\text { Молодежь выражает передовые идеи нашего времени, в том } \\
\text { числе и в вопросе об "улучшении» человека }\end{array}$} \\
\hline & $\Delta a$ & $\begin{array}{l}\text { Скорее да, } \\
\text { чем нет }\end{array}$ & $\begin{array}{l}\text { Трудно } \\
\text { сказать }\end{array}$ & $\begin{array}{c}\text { Скорее } \\
\text { нет, чем да }\end{array}$ & $\mathrm{Hem}$ \\
\hline биолог, медик & 19,9 & 35,9 & 30,1 & 10,3 & 3,8 \\
\hline другие специальности & 16,5 & 36,9 & 27,8 & 12,9 & 5,7 \\
\hline
\end{tabular}

Таким образом, уверенно выступают за эту позицию 19,9\% биологов-медиков и $16,5 \%$ молодых представителей других специальностей; больше склонны к этой позиции (скорее «да», чем «нет») 35,9\% биологов-медиков и $36,9 \%$ представителей других специальностей. Наметился парадокс: с одной стороны, взгляды на «улучшение человека» для молодых людей определяются в небольшой степени их профессиональными предпочтениями, с другой стороны, около половины и тех, и других считают, что именно молодежь выражает передовые идеи нашего времени. С этим парадоксом придется считаться всем тем, кто планирует акции в области «улучшения человека».

\section{ЗАКАЮЧЕНИЕ}

Исследование показало, что:

1. Неперспективными признаются молодежью те изменения в природе человека, которые покушаются на традиционные ценности российского общества. Здесь соди- 
дарны между собой как будущие представители биологической и медицинской науки, так и те, кто избрал своим будущим занятия другими гуманитарными науками.

2. Представители первой и второй группы слабо ориентируются в трансгуманистическом наборе ценностей изменения природы человека. Они скорее на интуитивном уровне представляют себе и то, что может быть поддержано в плане «улучшения человека», и то, что вызывает опасения и не кажется перспективным в изменении природы человека.

3. Аля молодых людей, размышляющих над будущим человека, остается вполне приемлемым то, что молодежь будет играть решающую роль в этих изменениях. Они не учитывают непрофессионализм рассуждений молодежи об «улучшении человека». Складывается парадоксальная ситуация, когда примитивное представление о перспективах человека приписывается наиболее активной части тех, кто будет эти перспективы осуществлять.

\section{СПИСОК АИТЕРАТУРЫ}

Гребенщикова, Е. Г. (2015) Ответственные исследования и инновации в биотехнонауке // Рабочие тетради по биоэтике. Вып. 21. М. : Изд-во МосГУ. С. 9-18.

Концепции постчеловека в философии и технонауки (2016): материалы V Междунар. науч. школы для молодежи. Белгород, 19-23 мая 2016 г. / под ред. С. М. Климовой, А. А. Майданского. Белгород : ИА «Белгород» НИУ «БелГУ». 245 с.

Аапшин, В. А. (2016) Пути развития человеческого потенциала под влиянием биомедицинских технологий (по мнению молодежи здоровой и с ограниченными возможностями по здоровью) // Знание. Понимание. Умение. № 3. С. 97-102. DOI: 10.17805/zpu.2016.3.7

Ауков, В. А. (2011) Биосоциология // Знание. Понимание. Умение. № 3. С. 322-326.

$\Lambda$ уков, В. А. (2015) «Улучшение» человека: взгляд молодежи // Рабочие тетради по биоэтике. Вып. 20. М. : Иза-во МосГУ. С. 42-65.

Ауков, Вал. А., Павлов, А. В. (2015) Конструирование человека в свете тезаурусной концепции молодежи [Электронный ресурс]// Информационный гуманитарный портал «Знание. Понимание. Умение». № 4 (июль - август). URL: http://zpu-journal.ru/e-zpu/2015/4/Lukov_Pavlov_Constructing-Man/ (дата обращения: 20.11.2016).

Малахова, Н. (2014) Ключевые факторы интеграции метода форсайта в систему управления исследованиями и разработками [Электронный ресурс] // Национальный исследовательский университет «Высшая школа экономики». 7 декабря. URL: https:/foresight.hse.ru/news/ 138924636.html (дата обращения: 20.11.2016).

Тищенко, П.А. (2014) Будущее: риск, судьба и статистика // Гуманитарные ориентиры научного познания / отв. ред. П. А. Тищенко. М. : Навигатор. 352 с. С. 336-340.

Тищенко, П. А., Юдин, Б. Г. (2015) Биоэтический анализ конвергентных технологий «улучшения» человека // Рабочие тетради по биоэтике. Вып. 20. М. : Изд-во МосГУ. С. 9-20.

Юдин, Б. Г. (2014) На пути к трансчеловеку // Гуманитарные ориентиры научного познания / отв. ред. П. А. Тищенко. М. : Навигатор. 352 с. С. 341-351.

Юдин, Б. Г. (2015) Трансдисциплинарный характер гуманитарной экспертизы // Трансдисциплинарность в философии и науке: подходы, проблемы, перспективы / под ред. В. Бажанова, Р. В. Шольца. М. : Навигатор. 564 с. С. 319-333.

FM-2030 (1970) Optimism One: The emerging radicalism. N. Y. : Norton. 249 p.

FM-2030 (1973) Up-Wingers: A Futurist Manifesto. N. Y. : John Day Co. 146 p.

FM-2030 (1977) Telespheres. N. Y. : Popular Library CBS Publications. 173 p. 


\section{PROSPECTS OF TRANSHUMANIST TECHNIQUES OF HUMAN ENHANCEMENT: YOUTH ASSESSMENTS \\ V. A. LUKOV \\ (MOSCOW UNIVERSITIES FOR HUMANITIES)}

The article examines the prospects of transhumanist techniques of human enhancements seen through the eyes of Russia's youth. The study is based on field research done in Anadyr, Belgorod, Bratsk, Ekaterinburg, Irkutsk, Kyzyl, Moscow, Novosibirsk, Oryol, Yakutsk and other cities of Russia by a team from Moscow University for the Humanities. The research classified respondents into two groups: those somehow linked to the field of human life improvement (majoring in medicine, biology, biotechnology, etc.) vs. those whose professional identity lies outside of this field (history, sociology, economics, management, etc.)

Our study showed that both groups held nearly identical views on the prospects of a number of transhumanist technologies of human enhancement. To an extent, the ones they consider unpromising are those currently being implemented.

Qualitative studies of the opinions of medicine majors and graduates of medicine universities, who are doing practical work in the field of human enhancement, have shown that questionnaire responses do not reflect personal views of how promising specific transhumanist technologies are. This is largely due to the respondents' tendency to prioritize mass ideas on human enhancement and its efficiency rather than their own experience.

Keywords: biosociology, transhumanism, youth in Russia, public opinion, professional identity

\section{REFERENCES}

Grebenshchikova, E. G. (2015) Otvetstvennye issledovaniia i innovatsii v biotekhnonauke. In: Rabocbie tetradi po bioetike, vol. 21. Moscow, MosGU Publ. Pp. 9-18. (In Russ.)

Kontseptsii postcheloveka $v$ filosotsii i tekbnonauki (2016): materialy V Mezbdunar. nauch. shkoly dlia molodezbi. Belgorod, 19-23 maia 2016 g., ed. S. M. Klimova and A. D. Maidanskii. Belgorod, ID «Belgorod» NIU «BelGU». 245 p. (In Russ.)

Lapshin, V. A. (2016) Puti razvitiia chelovecheskogo potentsiala pod vliianiem biomeditsinskikh tekhnologii (po mneniiu molodezhi zdorovoi i s ogranichennymi vozmozhnostiami po zdorov'iu). Znanie. Ponimanie. Umenie, no. 3, pp. 97-102. DOI: 10.17805/zpu.2016.3.7 (In Russ.)

Lukov, V. A. (2011) Biosotsiologiia. Znanie. Ponimanie. Umenie, no. 3, pp. 322-326. (In Russ.)

Lukov, V. A. (2015) «Uluchshenie» cheloveka: vzgliad molodezhi. In: Rabochie tetradi po bioetike, vol. 20. Moscow, MosGU Publ. Pp. 42-65. (In Russ.)

Lukov, Val. A. and Pavlov, A. V. (2015) Konstruirovanie cheloveka v svete tezaurusnoi kontseptsii molodezhi. Informatsionnyi gumanitarnyi portal "Znanie. Ponimanie. Umenie», no. 4 (July August) [online] Available at: http://zpu-journal.ru/e-zpu/2015/4/Lukov_Pavlov_ConstructingMan/ (access date: 20.11.2016). (In Russ.)

Malakhova, N. (2014) Kliuchevye faktory integratsii metoda forsaita v sistemu upravleniia issledovaniiami i razrabotkami. Natsional' nyi issledovatel' skii universitet "Vysshaia shkola ekonomiki”, 7 December [online] Available at: https://foresight.hse.ru/news/138924636.html (access date: 20.11.2016). (In Russ.)

Tishchenko, P. D. (2014) Budushchee: risk, sud'ba i statistika. In: Gumanitarnye orientiry nauchnogo poznaniia, ed. P. D. Tishchenko. Moscow, Navigator. 352 p. Pp. 336-340. (In Russ.)

Tishchenko, P. D. and Iudin, B. G. (2015) Bioeticheskii analiz konvergentnykh tekhnologii «uluchsheniia» cheloveka. In: Rabochie tetradi po bioetike, vol. 20. Moscow, MosGU Publ. Pp. 9-20. (In Russ.)

Iudin, B. G. (2014) Na puti k transcheloveku. In: Gumanitarnye orientiry nauchnogo poznaniia, ed. P. D. Tishchenko. Moscow, Navigator. 352 p. Pp. 341-351. (In Russ.)

Iudin, B. G. (2015) Transdistsiplinarnyi kharakter gumanitarnoi ekspertizy. In: Transdistsiplinarnost' $v$ filosofii $i$ nauke: podkbody, problemy, perspektivy, ed. V. Bazhanov and R. V. Shol'ts. Moscow, Navigator. 564 p. Pp. 319-333. (In Russ.)

FM-2030 (1970) Optimism One: The emerging radicalism. N. Y., Norton. 249 p. 
FM-2030 (1973) Up-Wingers: A Futurist Manifesto. N. Y., John Day Co. 146 p.

FM-2030 (1977) Telespheres. N. Y., Popular Library CBS Publications. 173 p.

Submission date: 20.11.2016.

Иуков Валерий Андреевич - доктор философских наук, профессор, директор Института фундаментальных и прикладных исследований Московского гуманитарного университета, заслуженный деятель науки Российской Федерации, вице-президент Международной академии наук (IAS, Инсбрук, Австрия), академик Международной академии наук педагогического образования. Адрес: 111395, Россия, г. Москва, ул. Юности, А. 5, корп. 6. Тел.: +7 (499) 374-75-95. Эл. aspec: v-lukov@list.ru

Lukov Valery Andreevich, Doctor of Philosophy, Professor, Director, Institute of Fundamental and Applied Studies, Moscow University for the Humanities; Honored Scientist of the Russian Federation; Vice President, International Academy of Science (Innsbruck, Austria); Full member, International Teacher's Training Academy of Science. Postal address: 5 Yunosti St., 111395 Moscow, Russian Federation. Tel.: +7 (499) 374-75-95. E-mail: v-lukov@list.ru 